\title{
AS GESTÕES MUNICIPAIS E O USO DAS INFORMAÇÕES NO PACTO PELA SAÚDE NO ESTADO DO RIO GRANDE DO NORTE
}

\author{
C.F.Melo', M.J.V.F.Leite, ${ }^{2}$, J.B.L.F.Carvalho ${ }^{3}$, E.R.Silva ${ }^{4}$, G.M.L.Aquino ${ }^{5}$, C.P.Macedo ${ }^{6}$ e F.H.M.A.Freire ${ }^{7}$. \\ ${ }_{1,6} \mathrm{Sec}$. de Estado da Saúde Pública/RN, ${ }^{2,3,4,5,7}$ Universidade Federal do Rio Grande do Norte \\ claudiafmelo@ig.com.br
}

Artigo submetido dezembro/2012 e aceito em janeiro/2013

\section{RESUMO}

O Pacto pela Saúde vem sendo para as gestões municipais uma experiência de grande relevância, em que uma nova forma de planejamento e avaliação tem sido proposta, com grande necessidade de utilização das informações em saúde. Este trabalho teve como objetivo analisar o uso das informações no planejamento e execução das ações de saúde. Foram selecionados onze municípios de diferentes portes populacionais e de diferentes regiões do Estado. As opiniões foram coletadas através de entrevistas semiestruturadas e analisadas em quatro categorias. As opiniões foram coletadas através de entrevistas semiestruturadas e analisadas em quatro categorias. Constatou-se que existe por parte dos gestores municipais uma avaliação positiva do processo de implantação do Pacto pela Saúde. Eles reconhecem a importância do uso das informações nos processos decisórios da gestão e aceitam as determinações impostas como naturais, sendo uma oportunidade de articulação e maior responsabilização. Identificaram, ainda, os principais problemas como propositivos, apresentando estratégias para superação dos mesmos para sua qualificação.

PALAVRAS-CHAVE: Pacto pela Saúde, Gestão em Saúde, Informações

\section{THE MUNICIPAL MANAGEMENT AND THE USE OF THE INFORMATION IN THE PACT FOR HEALTH IN THE STATE OF RIO GRANDE DO NORTE}

\begin{abstract}
The Pact for Health has been for the municipal management an experience of great importance, in that a new way of planning and evaluation has been proposed, with great need for use of information in health. This work aimed to analyze the use of the information in the planning and execution of the actions of health. It was selected eleven municipalities of different sizes and from different regions of the State. The opinions have been collected through semi-structured interviews, transcribed and analyzed in a way that is grouped into four
\end{abstract}

categories. It was noted that there is on the part of municipal officer a positive evaluation of the deployment process, considering the recognition as the importance of the use of the information in the decision making processes of management, as well as the acceptance of the determinations imposed as a natural opportunity for articulation and greater accountability. They identified the main problems and strategies for introducing propositional were overcoming the same for your qualification.

KEY-WORDS: Pact for Health, Health Management, Information 


\section{AS GESTÕES MUNICIPAIS E O USO DAS INFORMAÇÕES NO PACTO PELA SAÚDE NO ESTADO DO RIO GRANDE DO NORTE.}

\section{INTRODUÇÃO}

O Sistema Único de Saúde (SUS) ao longo dos seus 20 anos vem desenvolvendo tecnologias com a finalidade de aperfeiçoar suas formas de gestão com vistas à melhoria da qualificação da atenção à saúde da população e do seu fortalecimento. Tais iniciativas são extremamente importantes considerando a necessidade de atender aos seus princípios, especialmente o da descentralização, com comando único em cada esfera de governo. A este princípio tem sido atribuído um dos maiores méritos do SUS, onde a municipalização da saúde, a despeito dos problemas enfrentados, tem se traduzido em uma importante estratégia para ampliar cobertura e atender às demandas específicas da população local.

Por outro lado, se avalia que uma grande parte dos sistemas municipais não consegue atender de forma oportuna e qualificada as demandas da população, gerando uma necessidade de articulação com outros municípios e outros níveis de gestão, quais sejam as gestões estadual e federal.

Neste sentido, ao longo dos anos, alguns mecanismos de gestão intergovernamental foram implantados, dentre estes as Normas Operacionais Básicas. Estas foram criadas a partir da Lei Orgânica da Saúde, publicada em 1990. Estas normas foram instrumentos fundamentais para regulamentar a divisão de responsabilidades entre a União, Estados e Municípios, a relação entre os três níveis de governo e os mecanismos de financiamento, incluindo critérios e fluxos de recursos (OLIVEIRA, 2003; NORONHA, 2006).

Para conciliar as características do sistema federativo brasileiro e atender às diretrizes do SUS foram criadas a Comissão Intergestores Bipartite (CIB) e as Comissões Intergestores Regionais (CIRs) no âmbito estadual e a Comissão Intergestores Tripartite (CIT), no âmbito Federal. Estas Comissões atuam como espaços de negociação e pactuação de temas relativos à gestão do SUS e são compostas por representações dos governos estadual e municipais, no caso das $\mathrm{ClBs}$, dos governos municipais nas $\mathrm{ClRs}$ e dos governos federal, estaduais e municipais, no caso da CIT (VASCONCELOS, 2006; MACHADO, 2007; OLIVEIRA, 2003; NORONHA, 2006).

Através destas Normas, importantes instrumentos de pactuação foram estruturados, como a Programação Pactuada e Integrada da Assistência à Saúde; o Pacto da Atenção Básica, a Programação Pactuada Integrada da Vigilância em Saúde, entre outros. Estes instrumentos tinham como objetivo de registrar consensos na pactuação da prestação da assistência e da vigilância em saúde entre os municípios e o nível estadual e 
organizar o repasse financeiro, incluindo os serviços prestados pelo setor privado, em complementação ao SUS.

Além destes espaços, ainda podemos evidenciar como instâncias de articulação intergestores o Conselho Nacional de Secretários Estaduais de Saúde (CONASS), o Conselho Nacional de Secretários Municipais de Saúde (CONASEMS) e o Conselho Estadual de Secretários Municipais de Saúde (COSEMS).

A partir destas experiências, passou-se a ter necessidade de um redimensionamento destes mecanismos de articulação intergestores com avaliações de seu esgotamento e necessidade de novos direcionamentos. Em 2005, é iniciado um processo de avaliação e construção da proposta hoje definida como Pacto pela Saúde que surge a partir da avaliação das conquistas políticas e jurídicas no campo do direito à saúde e os avanços organizativos e assistenciais propiciados pela implantação do SUS que não foram suficientes para equacionar os problemas da atenção à saúde (VASCONCELOS, PASCHE, 2006).

O Pacto pela Saúde surge em 2006, através de um consenso entre o Ministério da Saúde, CONASS e CONASEMS em relação às responsabilidades dos três gestores do SUS no campo da gestão do sistema e da atenção à saúde. O mesmo foi firmado a partir de princípios comuns que guardam coerência com a diversidade operativa e tem as seguintes características: respeitar as diferenças loco-regionais; agregar os pactos anteriormente existentes; reforçar a organização das regiões sanitárias instituindo mecanismos de cogestão e planejamento regional; fortalecer os espaços e mecanismos de controle social; qualificar o acesso da população à atenção integral à saúde; redefinir os instrumentos de regulação, programação e avaliação; valorizar a macro-função de cooperação técnica entre os gestores; propor um financiamento tripartite que estimula critérios de equidade nas transferências fundo a fundo (BRASIL, 2006).

Este Pacto, nas suas três dimensões - Pacto pela Vida, em Defesa do SUS e de Gestão possibilita a efetivação de acordos entre as três esferas de gestão. O Pacto pela Vida se compromete com as prioridades que apresentam impacto sobre a situação de saúde da população brasileira; o Pacto em Defesa do SUS expressa compromissos com a consolidação da reforma sanitária brasileira, buscando desenvolver e articular ações para qualificar e assegurar o SUS como uma política pública e o Pacto de Gestão estabelece diretrizes para a gestão do sistema nos aspectos da descentralização; regionalização; financiamento; planejamento; programação pactuada e integrada; regulação; participação e controle social; gestão do trabalho e educação na saúde (BRASIL, 2006; CONASS, 2006).

Ainda no ano de 2006, por meio da Portaria/GM 699, foi estabelecida a unificação total dos processos de pactuação de indicadores para o ano de 2007 com vistas à melhoria do desempenho dos serviços e da situação de saúde da população bem como o monitoramento do Pacto pela Saúde, orientados por indicadores, objetivos, metas e responsabilidades, que compõem o Termo de Compromisso de Gestão. 
Em janeiro de 2007, a Portaria/GM 91 regulamentou a unificação do processo de pactuação de indicadores, integrando o Pacto da Atenção Básica com o pacto de indicadores da Programação Pactuada e Integrada da Vigilância em Saúde, que passou a ser denominada de Programação das Ações Prioritárias de Vigilância em Saúde, e os indicadores propostos no Pacto pela Saúde. Essa Portaria estabeleceu os indicadores do Pacto pela Saúde a serem pactuados por municípios, estados e Distrito Federal, levando em conta que as metas ou parâmetros nacionais dos indicadores do Pacto pela Saúde serviriam de referência para a definição das metas municipais, estaduais e do Distrito Federal, observadas as metas ou parâmetros estabelecidos para cada unidade da federação. Foi facultada aos municípios, estados e Distrito Federal a possibilidade de eleger outros indicadores de importância sanitária loco-regional, ou de propor alterações nas metas propostas para melhor adequação às especialidades locais.

Apesar dos avanços obtidos no Pacto pela Saúde onde é formalizada a necessidade de planejar e avaliar as ações de saúde através de indicadores de monitoramento se observa que os municípios se encontram em diferentes estágios de aprendizado e utilização das informações epidemiológicas no planejamento, monitoramento e avaliação dos serviços.

Neste sentido, o insuficiente uso das informações nos serviços de saúde tem sido objeto de vários estudos e contribuições teóricas. Por um lado, há clareza entre os autores quanto à importância e contribuição da epidemiologia no diagnóstico da situação de saúde, na vigilância em saúde e no planejamento e avaliação dos serviços, programas e tecnologias (PEREIRA, 2003; PALMEIRA, 2000; PINHEIRO, ESCOSTEGUY, 2009; DRUMOND JR, 2006; GALLO, BARBIERI, 2004).

Por outro lado, Gallo, Barbieri (2004) também evidenciam as dificuldades dos serviços de saúde de se apropriarem desta ferramenta em função das seguintes realidades:

ausência de profissionais de saúde devidamente preparados, em qualidade e quantidade suficientes para desenvolvê-la e utilizá-la de modo adequado; baixa valorização e incentivo por parte dos gestores, quanto à sua utilização; dificuldades relacionadas ao processo de trabalho em saúde (excesso de compromisso com a prestação da assistência; ausência de instrumentais necessários para utilização, como o equipamento de informática com acesso à internet).

No entanto, alguns autores relatam avanços, mesmo que ainda não satisfatórios, em relação a estas questões. Isto tem se dado pelas novas orientações de organizações de serviços, através da descentralização e por mecanismos de indução, como o Pacto pela Saúde. Segundo Drummond Jr (2006) "a descentralização reforça o papel dos municípios e unidades de saúde na condução da política de saúde exigindo criatividade tanto para o diagnóstico de problemas que consiga orientar a captação das especificidades nas suas 
áreas de atuação, quanto para as intervenções adequadas e oportunas para as diferentes situações encontradas".

No que diz respeito à avaliação dos serviços, as informações em saúde contribuem fortemente em desenhos de pesquisas avaliativas. Na área de saúde é tradicional a defesa da avaliação da qualidade com base no modelo proposto por Donabedian, que apresenta três componentes básicos: estrutura, processo e resultado (PEREIRA, 2003; PINHEIRO, ESCOSTEGUY, 2009; SCHRAIBER ET AL, 1999).

Assim, este artigo tem como objetivo analisar o uso das informações em saúde no planejamento e execução das ações de saúde nas gestões municipais no estado do Rio Grande do Norte.

\section{METODOLOGIA}

Este estudo, de caráter qualitativo, utilizou como sujeitos da pesquisa secretários de saúde e equipes gestoras de 11 secretarias municipais de saúde do Estado do Rio Grande do Norte. Estes municípios foram selecionados de forma intencional, a partir de critérios que levaram em consideração os compromissos e responsabilidades estabelecidos no Pacto pela Saúde no ano de 2006, a diversificação de portes e a distribuição geográfica.

Para a coleta de dados foi utilizada uma entrevista semiestruturada, com roteiro previamente definido e aplicada de forma individual, junto aos secretários de saúde dos municípios mais distantes da capital e de forma coletiva, junto aos secretários de saúde e equipes gestoras dos municípios mais próximos à capital e que se mostraram disponíveis para reunir sua equipe com esta finalidade específica. Ao final, foram contemplados dois municípios com população até 5.000 habitantes (Porte 1), dois municípios com população de 5.001 a 10.000 habitantes (Porte 2), dois municípios com população de 10.001 a 50.000 habitantes (Porte 3) e cinco municípios com população acima de 50.000 (Porte 4). Estes municípios contemplaram todas as regiões de saúde do Estado.

As questões das entrevistas foram baseadas em um roteiro que contemplava uma análise do processo de incorporação do uso das informações nas gestões municipais; avaliação das dificuldades e facilidades no uso das informações nas gestões municipais e condições que interferem no processo; as estratégias utilizadas para superação das dificuldades de formação dos profissionais nas áreas de informações em saúde/epidemiologia/planejamento nas gestões municipais; e por fim, uma avaliação do Pacto pela saúde como uma estratégia que demandou um maior uso das informações em saúde nas gestões municipais.

As entrevistas foram gravadas, posteriormente transcritas e analisadas, com base da identificação das falas de acordo com categorias estabelecidas a posteriori, construídas em coerência com o objetivo do estudo. Procedeu-se a construção do plano descritivo das falas, com destaque às similaridades e diferenças entre as opiniões ou 
relatos, considerando as diferenças entre os grupos a partir das características de sua composição. Com isso, foi possível proceder a análise de sentido e elaborar categorias a partir das falas, assim definidas: uso das informações nas gestões municipais; dificuldades e facilidades que interferem no processo; estratégias utilizadas para superação das dificuldades de formação de profissionais; potencial do Pacto pela Saúde enquanto indutor na demanda pelo uso da informação nas gestões municipais.

Este Projeto tomou como base as Diretrizes e Normas Regulamentadoras de Pesquisa em Seres Humanos/Resolução 196, de 10 de outubro de 1996, tendo sido aprovado pelo Comitê de Ética em Pesquisa da Universidade Federal do Rio Grande do Norte - CAAE 0090.0.051.000-09.

\section{RESULTADOS E DISCUSSÃO}

\section{Uso das Informações nas Gestões Municipais}

As opiniões quanto à avaliação do uso das informações enfatizam a importância do seu uso, considerando as informações imprescindíveis especialmente no planejamento e na vigilância em saúde. Esta ideia está bem demonstrada nas falas destes gestores:

“...Outra questão relevante é a gente ter esses dados em constante avaliação porque tem como a gente, na medida do possível, a vigilância em saúde ela estar traçando planos a partir de indicadores para conseguir alcançar alguns objetivos. Então é importante trabalhar com dados e esses dados vêm através dos sistemas de informações". (Município de Porte 1)

"O uso da informação em saúde eu diria que é primordial para que a gente possa estar desenvolvendo bem as nossas ações". (Município de Porte 4)

As falas dos gestores apontando a necessidade do uso das informações no planejamento em saúde se aproximam às ideias de Goldbaum (1996) ao afirmar que esta é uma tentativa histórica de superação da limitação do uso de informações para trabalhar com aspectos financeiros e contábeis da prestação de serviços, operando mais como instrumento administrativo do que como de avaliação.

Algumas falas, além de reforçarem a importância, evidenciam que também existem dificuldades, mas que estas não podem ser compreendidas como um entrave para o uso das informações. Este gestor representa esta opinião ao afirmar que:

"é impossível a gente ter capacidade para planejamento se a gente não usar dados e histórico de dados para que a gente possa 
formatar o que é que está sendo feito, o que é que a gente tem como realidade e que caminho a gente com esses dados em mão vai traçar para atingir o objetivo que a gente quer, que é aquele planejamento que estamos fazendo. Eu acho que não é fácil, é uma quantidade muito grande de programas que você precisa estar atualizando, seja na própria atenção básica, seja nas sedes das gestões. Mas, como você evoluir sem ter esses dados? Sem todos terem esse conhecimento? Precisamente até para se qualificar para poder planejar ações melhores." (Município de Porte 3)

Os gestores aceitam as determinações e obrigatoriedades relacionadas ao uso das informações em saúde, especialmente com a implementação do Pacto pela Saúde como naturais, encarando-as como oportunidades de articulação e maior responsabilização, não deixando de evidenciar que em alguns momentos ocorrem grandes dificuldades, considerando que a equipe não é preparada o suficiente para conduzir as ações, necessitando muitas vezes até contratar consultorias para atender às demandas técnicas. Estas ideias estão explicitadas nas falas dos seguintes gestores:

"Às vezes, assim, a gente é cobrado muito em cima, também. Tudo é para ontem. Mas é importante a gente saber que tem que cumprir, não é meramente um papel que a gente engaveta. Eu acho que também depende de cada realidade, de cada município, porque se você uma gestão que lhe apoia, que dá condições, acho que ficam mais fáceis as coisas, e se tem uma equipe, é muito importante". (Município de Porte 2)

“...é bem pouquinha gente que tem conhecimento e com vontade para estar absorvendo um trabalho que prá muita gente é tido como chato, não é? Mas de uma fundamental importância para o SUS." (Município de Porte 3)

Um aspecto positivo relatado pelos gestores foi que as rotinas do Pacto provocam a necessidade de articulação entre as equipes gestoras e as equipes locais

"Porque, assim, os Agentes [Comunitários de Saúde] visam muito a questão do Pacto, não é? O Agente parte para o trabalho de análise dos dados que está veiculado às metas para pactuar no Pacto. Daí o Agente começa a fazer o monitoramento, o Agente vai monitorando a razão de exames citopatológicos, não é. Então a gente aproveita esses momentos de reunião e tentar reunir toda a equipe." (Município de Porte 4) 


\section{Dificuldades e Facilidades que Interferem no Uso das Informações}

As dificuldades no uso das informações apontadas foram: baixa qualificação, vínculos precários, rotatividade e baixo empenho da equipe; condicionamento da não alimentação dos sistemas ao corte do repasse financeiro; não descentralização da alimentação dos SIS; infraestrutura de informática insuficiente; falta de integração dos SIS e baixa autonomia.

Quanto às facilidades, foram apontadas: disponibilidade de infraestrutura, oportunidade de acompanhamento das ações, disponibilidade das informações, existência de profissionais qualificados e com experiência. Algumas destas dificuldades e facilidades estão evidenciadas nas seguintes falas:

"Um quesito importante que a gente também pode mencionar não é Luciane, é a rotatividade dos profissionais. São muitos os profissionais capacitados pelas instâncias superiores, mas não têm oportunidades, devido não terem um contrato firmado pelo município na efetivação". (Município de Porte 4)

"A infraestrutura nós temos hoje... Hoje nós temos a secretaria com sala específica para atendimento ao público e a sala do gestor e também uma sala específica só para a equipe técnica para que eles possam na parte de ter um local mais ambientalizado na questão de programas, para atualizar programas, para discutir programas e trabalhar em conjunto." (Município de Porte 1)

A equipe gestora enfatiza a dificuldade de utilização de informações no planejamento das ações, declarando que este processo de planejamento tem ainda um agravante - Sempre é feito de forma muito rápida. Há uma avaliação que essas oportunidades não são rotineiras e exigem um grande esforço da equipe condutora. Estas ideias estão apresentadas nas seguintes falas:

"Quando a gente fala na questão de informações acho que a gente deixa muito a desejar... Eu acho que a gente nunca planeja em cima de dados e de informações porque essa questão de planejamento, ela acontece de uma maneira muito brusca." (Município de Porte 4)

"Existem as reuniões técnicas, não é? às vezes por categorias enfermeiros, dentistas, médicos... e existe também as que a gente convoca, justamente para estar trabalhando esses dados, estar sempre tentando aperfeiçoar de uma forma geral os indicadores de atenção básica, não é? Tudo a gente está sempre trabalhando. Mas nem tudo é assim, sabe como está na fala. É tudo muito 
trabalhado, muito suado, e não necessariamente acontece assim, vamos dizer, assim, com tanta rotina, não é? Tem essa rotina de chamar e tudo, mas haveria necessidade de estar sempre assim, com um agendamento mais fechado para nós mesmos, não é?" (Município de Porte 4)

Por outro lado, há um entendimento quanto à dificuldade do uso das informações e um questionamento quanto à validade do trabalho.

"A gente alimenta o sistema, mas a gente não usa a informação. Isso é uma critica que nós fazemos a nós mesmos porque é assim - a gente produz muitos dados, às vezes algumas informações. $E$ faz o que com isso?" (Município de Porte 4)

Este problema pode contribuir para outro, relatado por Portela, Teixeira (2011), que é a resistência às inovações. Os profissionais ao se depararem com a necessidade de realizarem novas ações que demandam a apropriação de novos processos de trabalho se sentem inseguros. Por outro lado, é evidente, e as falas dos gestores reforçam, que estas novas demandas exigem novas competências para estes profissionais. Desta forma, os gestores se veem instigados a desenvolverem estratégias junto às instituições formadoras ou ações educativas desenvolvidas na própria instituição para superar este problema.

Também são fortemente anunciadas as dificuldades relacionadas às equipes de trabalho. Além da rotatividade, anteriormente comentada, há declarações da própria ausência da equipe e de sua baixa qualificação, especialmente na área de informações em saúde. Isto leva algumas gestões municipais a contratarem assessorias externas para apoio às ações.

"Eu acho que as dificuldades dos municípios são grandes devido a esses três fatores: a ditadura de funcionários, o parque computacional e a capacitação desses profissionais. Então, por isso tem muitas falhas." (Município de Porte 4)

"Os municípios, aqueles que por sorte ou competência dos gestores tem uma equipe técnica, não é? Então, mais ou menos, dá uma equilibrada. Mas, mesmo assim, com essas dificuldades que nós temos aqui, principalmente em recursos humanos, não é? Para alimentar os sistemas de informações é difícil. (Município de Porte 4)

Em relação às questões acima relatadas, Portela, Teixeira (2011) questionam se as características da epidemiologia no processo de produção e compartilhamento do saber científico e tecnológico facilitam ou dificultam seu potencial de contribuir para a organização de serviços de saúde mais efetivos, equitativos e eficientes. Além disso, 
questionam se a gestão de saúde permite ou inibe a incorporação de símbolos, conhecimentos e instrumentais produzidos pela epidemiologia.

Neste aspecto, as falas dos gestores são claras no diagnóstico destas facilidades e dificuldades, com opiniões positivas em relação à possibilidade e até obrigatoriedade do uso dos conhecimentos epidemiológicos, especificamente das informações em saúde, na gestão dos serviços de saúde. Para os gestores participantes desta pesquisa há clareza de que os instrumentos, conhecimentos e símbolos, oriundos da epidemiologia podem ajudá-los nas suas ações.

Por outro lado, os gestores afirmaram que algumas ações de repasse das informações se consolidam. Elas se apresentam como oportunidades de integração entre a gestão e os profissionais que atuam na atenção à saúde. Nesta oportunidade as equipes locais recebem o retorno.

"Tem fóruns trimestrais de atenção básica que estamos sempre repassando as informações. Esse fórum é da atenção básica e ele chama representantes de toda a rede para participarem. A gente está sempre passando informações do pacto da atenção básica, não é? das vigilâncias. A gente está passando essas informações sempre tentando melhorar o que está falho, não é? Não é só o fato de passar informações." (Município de Porte 4)

\section{Estratégias Utilizadas para Superação das Dificuldades de Formação de Profissionais}

No que diz respeito às estratégias para superação das dificuldades de qualificação da equipe, os gestores indicaram a necessidade de educação permanente dos profissionais que já atuam nos serviços de saúde e prioridade na contratação de profissionais já qualificados para as áreas específicas.

Em relação a esta questão, Goldbaum (1996) alertava a ausência de profissionais devidamente preparados em qualidade e quantidade suficiente para desenvolver ações com base na epidemiologia, reforçando ainda que estas funções seriam pouco valorizadas no que diz respeito a uma adequada remuneração e também pela baixa disponibilidade de infraestrutura no processo de trabalho destes profissionais nos serviços de saúde.

Atualmente, a partir da fala dos gestores participantes desta pesquisa observa-se que em relação aos profissionais, infelizmente ainda não obtivemos mudanças satisfatórias, conforme mencionado anteriormente. No entanto, ocorreram relatos frequentes de melhoria de infraestrutura nos níveis centrais das secretarias municipais de saúde integrantes desta pesquisa.

Os relatos desta pesquisa demonstraram existir uma forte lacuna na educação permanente das equipes técnicas e uma continuidade na formação dos profissionais da 
saúde sem domínio dos conhecimentos na área de informações em saúde. Estes achados estão em consonância com o posicionamento de Moraes (2007) ao afirmar que em uma análise das grades curriculares de cursos na área de saúde identificou uma grande ausência de conteúdos nesta área. Quando presentes, os temas se restringiam a tratamento de dados e manuseio estatístico, onde a informação é tratada apenas como um instrumento a ser manejado, afirmando ainda que questões históricas, epistemológicas, políticas, econômicas e de gestão são sistematicamente omitidas nos poucos cursos que abordam os temas de informação e informática em saúde.

A rotatividade dos servidores e dos gestores na maior parte das gestões municipais influencia fortemente nesta questão, já que tanto há uma dificuldade inicialmente relacionada ao fato destes profissionais chegarem aos serviços de saúde sem a adequada qualificação na área, como o fato deles não permanecerem nos serviços por um tempo suficiente para adquirirem estes conhecimentos. Foi relatado ainda que alguns técnicos com maior domínio na área são objeto de interesse e até disputa entre municípios, com um alto grau de rotatividade.

Neste aspecto, o fato de contar com profissionais efetivos, por si só é um aspecto positivo, pois ele acumula os conhecimentos necessários ao exercício de sua função durante a sua experiência de trabalho e ainda se responsabiliza por repassar esses conhecimentos aos novos colegas de trabalho, se tornando um facilitador da educação permanente, no processo de trabalho. Apresentamos algumas falas relacionadas a essas opiniões:

“Eu tenho vários outros setores lá dentro de gente efetiva, de auxiliares administrativos efetivos que ficam localizados em setores estratégicos para alimentação desses dados - SINAN, SIA. Muitos desses dados são feitos por funcionários efetivos. Então foram capacitados. É um problema na questão gerencial, claro. Tem cargo comissionado que a gente pena quando alguém sai... Graças a Deus é um problema resolvido." (Município de Porte 3)

"Eu acho que é exatamente fazendo cursos, as capacitações, mostrando, vendo as questões das necessidades. A gente sente essa dificuldade porque a gente absorve esses profissionais, principalmente os recém-formados que vem da Universidade, a gente tem que todo um trabalho, repassar todas as informações e se preocupar com capacitações porque a universidade ainda não está preparando estes profissionais para a saúde pública do Brasil." (Município de Porte 4)

No entanto, Paim (2003) alerta quanto à necessidade de limitar a responsabilidade da qualificação profissional como variável para indução do uso da epidemiologia nos serviços de saúde ao afirmar que não basta o acúmulo de um saber, a 
existência da tecnologia ou a necessidade social. A influência na gestão e liderança podem ser variáveis a serem examinadas na análise das possibilidades de incorporação.

\title{
Potencial do Pacto enquanto Indutor na Demanda pelo Uso da Informação nas gestões municipais
}

Quanto ao potencial do Pacto na utilização de informações, afirmaram que as atuais Comissões Intergestores Regionais (CIRs) são espaços de troca de experiências, oportunidades de tratar assuntos pertinentes à região, de se informarem quanto às discussões realizadas em outras instâncias e afirmaram dificuldades relacionadas ao baixo fortalecimento e incompreensões quanto ao seu real papel.

“... Então é importante essa viabilidade, a questão da troca de informações no colegiado do gestor [CIR] quanto aos sistemas de seu município porque ele próprio pode dizer: o meu sistema de informação está com alguma falha, então outro já interage: o meu a resolutividade eu encontrei nesse local e aí vem facilitar e muito".(Município de Porte 1)

Viana et al (2008) reforça indiretamente a importância das CIRs enquanto instâncias formais de articulação intergovernamental na política de regionalização do SUS, afirmando que

\begin{abstract}
"a descentralização e sua face regionalizadora são de suma importância para o processo de planejamento do território nacional. A imensidão do Brasil e suas históricas desigualdades requerem políticas públicas de fôlego para a diminuição das iniqüidades atrelada a um projeto nacional de desenvolvimento. $E$ para que essas políticas sejam efetivas e coerentes com a realidade de cada lugar, a regionalização se mostra um instrumento imprescindível para o planejamento. As desigualdades não devem ser vistas como um empecilho para a regionalização do SUS, pelo contrário, é por conta delas que se faz cada vez mais urgente uma regionalização de fato do sistema e da política."
\end{abstract}

Desta forma, a despeito das dificuldades vivenciadas pelas gestões municipais, alternativas de apoio e suporte às gestões municipais têm sido implementadas e consideradas importantes. Estas iniciativas visam atender aos princípios do Pacto pela Saúde, especialmente no que diz respeito ao princípio da cooperação, ou seja a criação de mecanismos institucionais que promovam a articulação e a pactuação para o desenvolvimento das ações e serviços de natureza regional, inclusive cofinanciamento (MACHADO et al, 2009).

Os gestores consideram o Pacto pela Saúde como uma estratégia que veio alterar significativamente os rumos do Sistema Único de Saúde. Através dele se sentiram 
instigados a reconhecerem o papel das informações em saúde na gestão dos serviços de saúde. Esta ideia está expressa nas falas dos secretários:

"O Pacto foi realmente um despertar para que o gestor tivesse esse cuidado de estar dizendo - olhe todo dia eu tenho que fazer meu dever de casa, que é o que? É estar trabalhando com as equipes, estar vendo as coberturas vacinais, estar vendo as notificações dos agravos, estar vendo os tratamentos de tuberculose. Estar acompanhando cada paciente dentro do seu território, na tentativa de atingir essas metas." (Município de Porte 4)

Em uma das entrevistas coletivas foi relatado pelo grupo a oportunidade do Pacto permitir discutir as pactuações municipais com as outras instâncias do SUS, no caso, com a Secretaria Estadual.

"O pilar, como ponto de partida, é o Pacto e os indicadores que a gente pactuou. Nos indicadores a gente sempre vê as séries históricas, não é? A gente trabalha muito com séries históricas. A gente faz um embate muito grande com o Estado [Secretaria Estadual]. O Estado, no momento da pactuação que é feita entre Estado e Municípios, o Estado sempre traz uma meta, não é? E o município às vezes vê que aquilo ali é uma meta inatingível para as condições municípios, não é?" (Município de Porte 4)

As secretarias municipais enfatizam a importância das equipes locais compreenderem a importância de pactuar e desenvolver esforços para atingir as metas e ainda apresentam algumas experiências diferenciadas, como a estruturação de salas de situação.

"Porque, assim, eles introduzem essas informações no sistema. Se eles não se sentirem corresponsáveis por isso a gente não vai conseguir, vai ser o simples fato de só alimentar o sistema. Aí a gente tem que introduzi-los como corresponsáveis." (Município de Porte 4)

“Eles já estão até com a salinha de situação. Foi fantástico a vinda da equipe porque o município trabalhou bem essa questão do monitoramento, de monitorar os indicadores que estão lá no setor de enfermagem, não é? Cada Unidade cria sua solicitação. Aos poucos os profissionais estão começando a visualizar que não é só atender. Então eles começam a sentar um pouco para planejar, diante desse sala de situação.(Município de Porte 4)

Há um reconhecimento que tanto o Pacto como outras orientações do Governo, como o Programa Nacional de Melhoria do Acesso e da Qualidade da Atenção 
Básica (PMAQ) exige a utilização de informações no processo de planejamento e monitoramento.

"A gente sabe que o PMAQ, na fala de vocês fica entendido, que ele veio potencializar algo que já deveria estar sendo feito e que não vinha sendo realizado. Então ele entra, potencializa e acredita mais ainda na questão do uso da informação para você gerar ações e ações que serão mais efetivas, não é? (Município de Porte 4)

Ao serem instigados quanto a uma avaliação da participação dos municípios neste processo, eles afirmam que apesar de terem melhorado o seu desempenho, essa melhora não acontece na mesma proporção do Ministério da Saúde. Declaram que isto ocorre em função das dificuldades conjunturais e das dificuldades das gestões municipais.

"Eu acho que os municípios evoluíram. Claro que ele tenha a evolução, isso é normal, devido à globalização. Mas é uma evolução que parte do Ministério da Saúde. Agora, o município não acompanhou a evolução do Ministério da Saúde, a nível tecnicamente, de infraestrutura. Por quê? Aí a gente já vai entrar nas dificuldades da crise financeira que ocorreu no término desses quatro anos, principalmente nos dois primeiros. Tem essa questão. Teve uma melhora no terceiro ano. Agora, este ano começou devido à crise famosa, no restante do mundo. Temos a questão também do INSS descontado na fonte e também a queda do IPI. Com isso a prefeitura, sua arrecadação, o repasse por parte do governo e principalmente o FUSERN o fundo único de saúde, fez com que o município ne tivesse e tenha até hoje essas grandes dificuldades para acompanhar a evolução do Ministério.(Município de Porte 4)

Os achados desta pesquisa corroboram as afirmações de Goldbaum (1996) quanto à maior participação dos municípios, a partir do processo de descentralização do SUS no sentido de uma maior responsabilidade administrativa, especificamente obrigando os municípios a incorporarem de modo ativo a epidemiologia para responder adequadamente às novas formas de condução das ações de saúde.

Por outro lado, cabe lembrar o alerta de PAIM (2003) para que se evite que os níveis estaduais e municipais reproduzam mecanicamente as estruturas federais, confinando a epidemiologia a alguns espaços restritos do SUS. Assim, conforme o mesmo autor se faz necessário "evitar uma epidemiologia dos 'de cima' para reproduzir seus 
privilégios e exclusão social e apontar para uma epidemiologia dos 'de baixo' para produzir informação e poder em busca de equidade e efetividade".

\section{CONSIDERAÇÕES FINAIS}

Este estudo permitiu identificar que existem diferenças regionais e relativas ao porte populacional dos municípios na forma como cada um vivencia suas dificuldades e como definem as estratégias de superação, principalmente entre o conjunto de municípios até 50.000 mil habitantes (porte 1, 2 e 3) e os acima de 50.000 mil (porte 4).

Quando se refere à utilização das informações, os municípios de porte 4 possuem a seu favor a descentralização dos Sistemas de Informação que permite um monitoramento mais efetivo das ações, considerando que o dado gerado seja oportunamente transformado em informação. Por outro lado, a descentralização por si só não garante uma melhor utilização da informação e nem uma maior qualificação das demandas da população, visto que os compromissos assumidos são mais complexos. Assim sendo, exige-se de cada gestor uma maior capacidade gerencial para potencializar, de forma adequada, a utilização da informação para a qualificação da atenção à saúde da população, bem como o fortalecimento da própria gestão.

Descentralizar sistemas e ações dentro do próprio município é outro desafio para esse grupo de municipios considerando o quantitativo de serviços existentes e a infraestrutura inadequada em relação aos equipamentos de informática e acesso à internet. Dessa forma, o trabalho de alimentação dos sistemas de informações é centralizado nas sedes das respectivas secretarias municipais, que em raras situações retornam as informações para as equipes locais, inclusive na capital do estado.

Em relação às estratégias de superação das dificuldades, os municípios de maior porte populacional assumem a responsabilidade principalmente em relação à qualificação das equipes, enquanto que nos municípios menores, existe uma maior dependência das gestões estadual e federal quanto a esta oferta.

A necessidade de qualificação das equipes é um consenso, independente do porte do município. Entretanto, devido ao número de profissionais nos municípios de maior porte, as discussões são realizadas através de fóruns, ou durante o período do cumprimento da avaliação dos indicadores do pacto, considerado insuficiente e restrito a uma representação das equipes. Há uma fragmentação dos processos, que são pontuais. A gestão tem grande importância, o modo como é conduzido o processo.

Finalizando, identificou-se que há uma avaliação positiva por parte dos secretários municipais de saúde e das equipes gestoras quanto ao processo de implantação do Pacto pela Saúde no estado. De uma forma geral, há um reconhecimento da importância da informação enquanto instrumento necessário para o planejamento da gestão, bem como, da ampliação da capacidade de diagnosticar as dificuldades ora vivenciadas e encontrar 
nos espaços coletivos institucionais, as estratégias de superação das mesmas, independente do porte populacional dos municípios.

\section{REFERÊNCIAS}

1. BRASIL. Ministério da Saúde. Secretaria Executiva. Departamento de Apoio à Descentralização. Coordenação-Geral de apoio à Gestão Descentralizada. Diretrizes Operacionais dos Pactos pela Vida, em Defesa do SUS e de Gestão. Brasília: Ministério da Saúde, 2006.

2. CONSELHO NACIONAL DE SECRETÁRIOS ESTADUAIS DE SAÚDE. Seminário do CONASS - Para entender o Pacto pela Saúde. Legislação referente ao Pacto pela Saúde 2006, http://www.conass.org.br>. Acesso em: 08/06/2009.

3. DRUMOND JR, M. Epidemiologia em Serviços de Saúde. In: CAMPOS, G.W.S ET al. Tratado de Saúde Coletiva. São Paulo: Hucitec, Rio de Janeiro: Ed.Fiocruz, 2006.

4. GALLO, D.L.L, BARBIERI, F.B. Epidemiologia e Serviços de Saúde.Rev.Olho Mágico. Londrina, v.11, n1/2, p.3-8, jan/jun, 2004.

5. GOLDBAUM, M. Epidemiologia e serviços de saúde. Cad. Saúde Pública. Rio de Janeiro, 12(Supl. 2):95-98, 1996.

6. MACHADO, C.V., LIMA, L.D., BAPTISTA T.W.F. Configuração Institucional e o papel dos Gestores no Sistema Único de Saude. In: MOTTA, G.C., PONTES, A.L.M. A organização e a operacionalização do Sistema Único de Saúde. Rio de Janeiro: EPSJV/FIOCRUZ, 2007.

7. MACHADO, R. R. et al. Entendendo o pacto pela saúde na gestão do SUS e refletindo sua implementação. Rev. Eletr. Enf. [Internet]. 2009; 11(1):181-7. Available from: http://www.fen.ufg.br/revista/v11/n1/v11n1a23.htm.

8. MORAES, I. H. S. Informação e informática em saúde: caleidoscópio contemporâneo da saúde. Ciência \& Saúde Coletiva. 12 (3): 553-565, 2007.

9. NORONHA, J.C, LIMA, L.D, MACHADO C.V. A Gestão do Sistema Único de Saúde: características e tendências. In: BRASIL. Ministério da Saúde. Saúde no Brasil: contribuições para a Agenda de Prioridades de Pesquisa. Brasília: Ministério da Saúde, 2006.

10. OLIVEIRA, M.H.C.B. Pactos de Gestão: divisão de responsabilidades entre Estados e Municípios na descentralização. In: PIERANTONI, C.R, VIANNA, C.M (Org). Gestão de Sistemas de Saúde. Rio de Janeiro: UERJ, Instituto de Medicina Social, 2003.

11. PALMEIRA, G. Epidemiologia. In: ROZENFELD, S (Org). Fundamentos de Vigilância Sanitária. Rio de Janeiro: Editora FIOCRUZ, 2000.

12. PAIM, J. S. Epidemiologia e planejamento: a recomposição das práticas epidemiológicas na gestão do SUS. Ciência \& Saúde Coletiva. 8 (2): 557-567.2003

13. PEREIRA, M.G. Métodos empregados em Epidemiologia. In: PEREIRA, M.G. Epidemiologia Teoria e Prática. Rio de Janeiro: Editora Guanabara Koogan S.A., 2003.

14. PINHEIRO, R.S., ESCOSTEGUY, C.C. Epidemiologia e Serviços de Saúde. In: MEDRONHO, R.A et al. Epidemiologia. São Paulo: Editora Ateneu, 2009. 
15. PORTELA, L.E., TEIXEIRA, C.T. Epidemiologia e Gestão de Serviços de Saúde. Cap. 57, p.622 a 630. In: ALMEIDA FILHO, N., BARRETO, M.L. Epidemiologia \& Saúde: fundamentos, métodos, aplicações. Rio de Janeiro: Guanabara Koogan, 2011.

16. SCHRAIBER, L.B. et al. Planejamento, gestão e avaliação em saúde: identificando problemas. In: Rev.Ciência\&Saúde Coletiva. 4 (2): 221-242, 1999.

17. VASCONCELOS, C.M. Política e Gestão no SUS: uma interação conflitiva. In: CASTRO, J.L, FORMIGA, J. M.M, VILAR,R.L.A (org).Política e Gestão em Saúde: reflexões e estudos. Natal: Editora Observatório RH NESC/UFRN, 2006.

18. VASCONCELOS, C.M., PASCHE, D.F. O Sistema Único de Saúde. In: CAMPOS, G.W.S ET al. Tratado de Saúde Coletiva. São Paulo: Hucitec, Rio de Janeiro: Ed. Fiocruz, 2006.

19. VIANA, A. L. A et al. Novas perspectivas para a regionalização da saúde. São Paulo em Perspectiva, v. 22, n. 1, p. 92-106, jan./jun. 2008.

\section{AGRADECIMENTOS}

Agradecemos ao Conselho Nacional de Desenvolvimento Científico e Tecnológico, ao Ministério da Saúde, à Secretaria de Estado da Saúde Pública do Rio Grande do Norte e à Fundação de Apoio à Pesquisa do Rio Grande do Norte pelo financiamento desta Pesquisa, com recursos do Programa Pesquisa para o SUS (PPSUS). 